\title{
Descriptions of adults, immature stages and venom apparatus of two new species of Dacnusini: Chorebus pseudoasphodeli sp. n., parasitic on Phytomyza chaerophili Kaltenbach and $C$. pseudoasramenes sp. n., parasitic on Cerodontha phragmitophila Hering (Hymenoptera: Braconidae: Alysiinae; Diptera: Agromyzidae)
}

\author{
Josep TORMOS ${ }^{1}$, Xavier PARDO $^{2}$, Ricardo JIMÉNEZ ${ }^{2}$, Josep Daniel ASÍS ${ }^{1}$ and SeVEriano F. GAYUBO ${ }^{1}$
}

${ }^{1}$ Unidad de Zoología, Departamento de Biología Animal, Facultad de Biología, Universidad de Salamanca, 37071-Salamanca, Spain; e-mail: tormos@gugu.usal.es

${ }^{2}$ Laboratori d'Entomologia, Departament de Biologia Animal, Universitat de València, Dr. Moliner, 50, 46100-València, Spain

Key words. Hymenoptera, Braconidae, new species, hosts, immature stages, venom apparatus, Spain

\begin{abstract}
The imagines, cast skin of the final larval instar, and venom apparatus of Chorebus pseudoasphodeli sp. n., an endoparasitoid of Phytomyza chaerophylli Kaltenbach, 1856 on Daucus carota L., and Chorebus pseudoasramenes sp. $\mathrm{n}$., an endoparasitoid of Cerodontha phragmitophila Hering, 1935 on Arundo donax L., two new species of Dacnusini from Spain, are described, illustrated, and compared with those of allied species. The immature larvae, mature larva, and pupa of C. pseudoasphodeli sp. n. are also described, illustrated, and compared. Morphological structures of phylogenetic value are discussed, and keys for the discrimination of the imagines are provided.
\end{abstract}

\section{INTRODUCTION}

The Alysiinae, a subfamily of braconid wasps, are largely characterized by their so-called "exodont" mandibles, a condition in which the teeth of the mandibles face anteriorly and do not overlap when the mandibles are closed (Wharton et al., 1997). They are believed to use these to emerge from the puparia of the cyclorrhaphous Diptera that they parasitize.

This subfamily has traditionally been divided into the tribes Alysiini (with three submarginal cells) and Dacnusini (with two submarginal cells). The latter lack the $\mathrm{r}-\mathrm{m}$ vein. Chorebus Haliday, 1833 is the largest genus of the Dacnusini with approximately 215 Holarctic species, and can be defined as follows: mandibles with four teeth, or metapleuron with a rosette of setae around a central swelling; most species have both characters (Griffiths, 1968; Tobias, 1995). The additional tooth is located between the middle tooth and the original lower tooth (the four-toothed mandibles of other Dacnusini have developed the additional tooth in a different position: on the dorsal side of the elongate 2 nd tooth). The rosette of setae around a swelling on the metapleuron and 4-toothed mandibles do not appear together in all species. Species of Chorebus are solitary endoparasitoids of Agromyzidae and Ephydridae (Diptera).

Most of the taxonomy of braconid wasps is based on adult external morphology, and relatively little attention has been given to interspecific differences in larval or internal characters even though they could be useful.

In this respect the Alysiinae, and hence the Dacnusini, have received little attention. Thus, for the genus Chorebus, only the last larval instar of seven species are described: C. aquaticus Muesebeck, 1950 and C. avesta (Nixon, 1944) by Čapek (1970); C. posticus (Haliday, 1839) (= C. "gracilis" (Nees von Esenbeck, 1834)) by Wright et al. (1946) and Short (1952); C. merella (Nixon, 1937), C. nana (Nixon, 1943) and C. nydia (Nixon, 1937) by Capek (1970) and $C$. denticurvatus Pardo, Tormos \& Verdú, 2001 by Pardo et al. (2001). Of these seven species, only in that of $C$. denticurvatus, in C. posticus are succinctly described by Wright et al. (1946), have been extensively described the morphological characters of the head (sclerotized mouthparts and supporting rods), spiracles (usually the prothoracic one) and tegument, which are important for the characterisation of the preimaginal stages of Hymenoptera Parasitica (Short, 1978; Finlayson, 1987). Of the immature larvae, only those of C. posticus are known (Wright et al., 1946).

The reproductive apparatus of Hymenoptera, and its associated venom apparatus, vary in ways that may provide phylogenetic information and be useful for discriminating closely related species (Edson \& Vinson, 1979; Quicke \& Achterberg, 1990; Whitfield, 1992). For the Dacnusini, detailed studies of variation in the gland and morphology of the reservoir of the venom apparatus have so far only been done by Quicke et al. (1997).

In this report the imagines, cast skin of the final larval instar and venom apparatus are described for two new species of Dacnusini that the authors discovered in Spain parasitizing agromyzid hosts: Chorebus pseudoasphodeli sp. n., and Chorebus pseudoasramenes sp. n. The immature larvae (first, second instars), mature larva (third instar) and pupa of C. pseudoasphodeli are also described. Additionally, the hosts of both species are cited, together with their host plants. 


\section{MATERIAL AND METHODS}

Imagos and exuviae of the final larval instar of C. pseudoasphodeli sp. n. were obtained in August 1988 from pupae of Phytomyza chaerophylli Kaltenbach, 1856, whose larvae were found mining the leaves of Daucus carota L., at Foyos (Valencia, Spain). Imagos and exuviae of the final larval instar of $C$. pseudoasramenes $\mathrm{sp} . \mathrm{n}$. were obtained in June 1989, from pupae of Cerodontha phragmitophila Hering, 1935, on Arundo donax L., at El Puig (Valencia, Spain). In both cases plant material infested with the host larvae was collected; this was placed in plastic bottles, of suitable dimensions, whose openings were covered with gauze held in place with a rubber band. These bottles were kept under ambient conditions of temperature, RH and photoperiod. The methodology used for opening the puparia and preparing the cast skins is that proposed by Wahl (1984).

For study of the egg and larval instars of C. pseudoasphodeli, leaves of $D$. carota L. mined by Phytomyza chaerophylli were collected in June 1990; these leaves were taken to the laboratory and placed in the same type of bottle as those described above, which were then kept in ambient conditions. The parasitoids that emerged from the host puparia were offered blotting paper impregnated with honey or sugar-water as a source food. Females, aged between 24-72 hours, were placed individually in Petri dishes $(9 \times 1.5 \mathrm{~cm})$ and provided daily with leaves of $D$ carota infested with different larval instars of $P$. chaerophylli. To obtain recently deposited eggs of $C$. pseudoasphodeli the host larvae were dissected immediately after oviposition. To study the larval development of the parasitoid, parasitized material was kept in a chamber at $21-23^{\circ} \mathrm{C}, 60-80 \mathrm{RH}$, and a photoperiod of $16 \mathrm{~L}: 8 \mathrm{D}$, and the hosts periodically dissected. When possible, these observations were complemented with dissection of hosts parasitized in the field. All dissections were carried out in $0.9 \%$ saline solution. For development of the egg and larvae, the methodology used by Guppy \& Meloche (1987) was followed. The microscopic preparations of the three larval instars were prepared by following the method of Evans (1987) and Sime \& Wahl (1998).

The venom apparatus of both species was prepared and illustrated according to the method described by Quicke et al. (1992, 1997) (chlorazol black method) for dry museum specimens. The venom apparatus, of one specimen of each species, was treated with hydroxide solution, which removed the soft tissue so that the remaining characters of the chitinous gland intima can be seen (these characters are not apparent when an intact gland and reservoir is examined).

The morphological terms for the body of the imago and wing venation follow Wharton et al. (1997); the biometric data follow Wharton (1977). The terminology used to refer to the different structures of the immature stages is that of Finlayson \& Hagen (1979), Hagen (1964), Short (1978), and Sime \& Wahl (1998). The characters of the gland and reservoir parts of the venom apparatus studied were as follows: a) the presence/ absence of an unsculptured region anterior to the reservoir, b) the number of reservoir subdivisions, c) the reservoir neck region: 1) without narrowing, 2) parallel-sided neck, 3) with such a neck, d) reservoir: 1) less than 4 times longer than maximal width, 2) 4-6 times longer than maximal width, 3) more than 6 times longer than maximal width (all excluding the anterior unsculptured bulb, e) secondary venom duct with annular/spiral sculpture: 1) absent, 2) distinct but not extensive, 3) well developed and extensive, f) venom gland: 1) extensively branched or with multiple filaments or sacks not separated by two long unbranched ducts after division of secondary venom duct, 2) with extensive branching or numerous sacks at the end of a pair of long tertiary ducts, 3) with only one pair of unbranched filaments, 4) with a single filament, g) venom gland inserted on reservoir: 1) before posterior end, 2) at extreme posterior end, h) secondary venom duct: 1) not narrow, more or less gradually developing into gland filaments, 2) narrow, terminating abruptly at globular glandular sacks. The terminology used follows Quicke et al. (1997) (Fig. 6). All the material examined (imagines, immature stages and venom apparatus) is deposited at the Facultad de Biología, Universidad de Valencia (Valencia, Spain). The following abbreviations were used for the preimaginal stage descriptions: $d=$ diameter; $\mathrm{h}=$ height; $1=$ length and $w=$ width.

\section{RESULTS AND CONCLUSIONS}

\section{ADULTS}

\section{Chorebus pseudoasphodeli sp. $\mathbf{n}$.}

(Figs 1a, 1b, 1c)

Type material. Holotype: female, SPAIN, Valencia, Foyos, 25-VIII-1988. Paratypes: SPAIN, Valencia, Foyos, 22-VIII1988, $10^{\circ}$; ditto, 25-VIII-1988, 2 우 우.

Host. Phytomyza chaerophylli Kaltenbach, 1856 on Daucus carota $\mathbf{L}$.

Female. Head transverse, in dorsal view between eyes 1.8-1.9 times as wide as long; 2-2.1 times as wide as face; 1.3-1.4 times as wide as mesoscutum; face 1.1-1.2 times as wide as high; eyes, in lateral view, 1.2 times as long as temples. Face with short pubescence, directed both towards the centre and downwards. Mandibles (Fig. 1a) slightly expanded towards their apex, 1.2 times as long as wide, with all four teeth well developed. Antennae as long as body, with 18 flagellomeres (20 antennomeres).

Mesosoma 1.6-1.7 times as long as wide. Sides of pronotum bare. Mesoscutum 1.1 times as wide as long, roughened anteriorly, with white pubescence covering its anterior face and median lobe, but lateral lobes with only pubescence anteriorly, notauli only on declivity. Metapleuron smooth, with a swelling displaying a rosette of poorly developed setae that only show a weak tendency towards differentiation in the direction of the setae. Propodeum rugose-punctate with most of its surface covered with a dense and fine pubescence. Hind femur 0.75 times as long as hind tibia; hind tibia 1.05 times as long as hind tarsus.

Wings. RS very slightly sinuate. 2-1A totally decoloured (Fig. 1b). Wing length: $2.5 \mathrm{~mm}$.

Metasoma. Petiole (Fig. 1c) slightly broadened towards apex, 1.2 times as long as wide apically. Tergite 2 without basal setae.

Colour. Body black, with exception of: palpi yellow; labrum yellow-brown; centre of mandibles reddishorange; antennae dark brown, excepting scape, pedicel, and basal half of first flagellomere, which are orangeyellow; legs orange-yellow; second metasomal segment orange-yellow.

Body length $1.77 \mathrm{~mm}$

Male. Like female but with: a) longer antennae, with 19 flagellomeres (22 antennomeres, b) petiole more stylized, 1.8 times as long as wide apically, with almost par- 


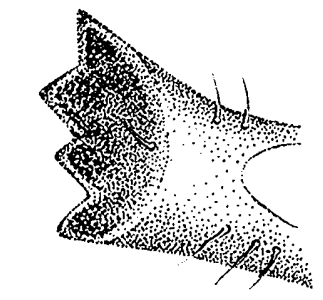

$1 \mathrm{a}$

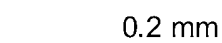

$0.2 \mathrm{~mm}$
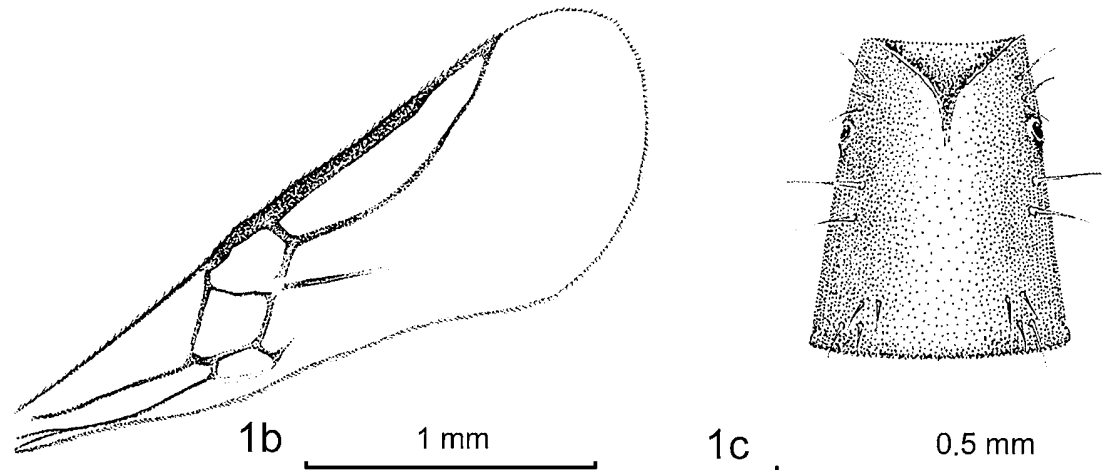

$1 \mathrm{c}$

$0.5 \mathrm{~mm}$

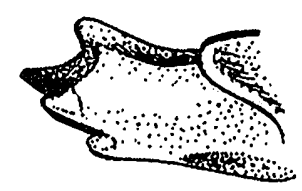

$2 a$ $0.05 \mathrm{~mm}$

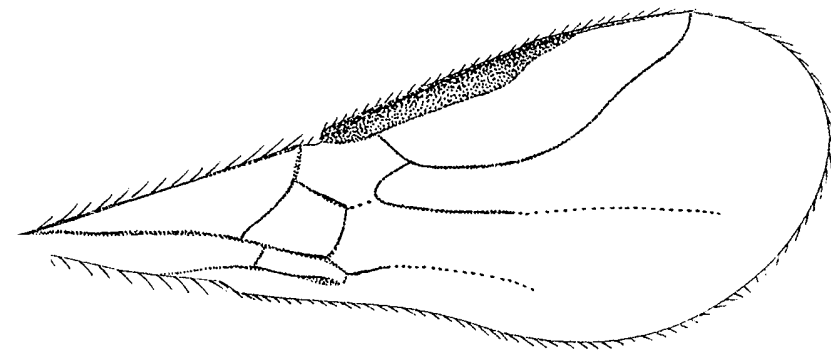

$2 b$

$1 \mathrm{~mm}$

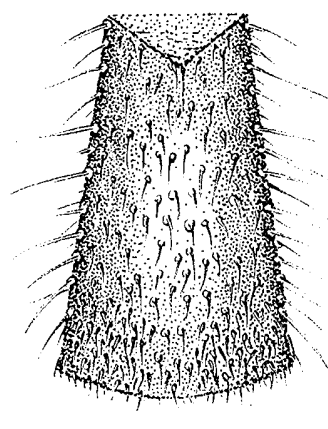

2c

$0.5 \mathrm{~mm}$

Figs 1-2. 1 - Chorebus pseudoasphodeli sp. $\mathrm{n}$. a - left mandible of adult; $\mathrm{b}$ - anterior right wing; $\mathrm{c}$ - petiole. 2 - Chorebus pseudoasramenes sp. $\mathrm{n}$. $\mathrm{a}$ - left mandible of adult; $\mathrm{b}$ - anterior right wing; $\mathrm{c}-$ petiole.

allel sides, and with more pronounced stigmatiferous tubercles; c) shorter: $1.55 \mathrm{~mm}$.

Differential diagnosis. This new species, in which the swelling of the metapleuron is smooth with a poorly developed rosette of setae, is included in the "plesiomorph species of Chorebus" (Griffiths, 1968), and is closest to $C$. asphodeli Griffiths, 1968, from which it is distinguished by the following characters: 1) antennae as long as body; 2) sides of pronotum bare; 3) wings with 2-1A totally decoloured; 4) metapleuron smooth; 5) colour: a) labrum (yellow-brown), b) palpi (yellow), c) centre of mandibles (orange-red), d) antennae (dark brown, with the exception of scape, pedicel, and basal half of first article of the flagellum, which are orangeyellow), e) legs (orange-yellow) and f) second metasomal segment (orange-red).

This species can be inserted in the keys of Griffiths (1968) (Part VI: 119) and Tobias (1995) (Vol. (III), Part $\mathrm{V}: 291)$ as follows:

\section{Griffiths (1968):}

15 Antennae shorter than body; antennal segments: $q, 23-24$ Wings with RS sinuate and 2-1A clearly developed (Griffiths: couplet V, 1968: 31, Fig. 178). Metapleuron slightly rugose on its lower half. Host: Liriomyza asphodeli Spencer, 1957 ........................ C. asphodeli

15' Antennae as long as body; antennal segments: ㅇ, 20; o, 22. Wings (Fig. 1b). Metapleuron smooth. Host: Phytomyza chaerophylli. Spain ......... C. pseudoasphodeli sp. n.

Tobias (1995):
75(76)Antennae 23-24 segmented (male not known). Sides of metathorax in lower half slightly rugose. Fig. 121: 6. Body length $2.2 \mathrm{~mm}$. Parasite of Liriomyza asphodeli. Spain ....

C. (S.) asphodeli

75(76')Antennal segments: $₹, 20 ; \delta^{\circ}, 22$. Sides of metathorax in lower half smooth. Body length: $\circ: 1.77 \mathrm{~mm} ;$ o: $1.55 \mathrm{~mm}$. Parasite of Phytomyza chaerophylli. Spain ........... ..................... (S.) pseudoasphodeli sp. n.

Etymology. The specific name of this species refers to $C$. asphodeli Griffiths, 1968, which it strongly resembles.

\section{Chorebus pseudoasramenes sp. $\mathbf{n}$.}

(Fig. 2a, 2b, 2c)

Type material. Holotype: female, SPAIN, Valencia, El Puig, 16-VI-1989. Paratypes: SPAIN, Valencia, El Puig, 15-VI-1989, 1o; ditto, 17-VI-1989, 1 우.

Host. Cerodontha phragmitophila Hering, 1935 on Arundo donax $\mathrm{L}$.

Female. Head transverse, in dorsal view, between eyes 2-2.1 times as wide as long; 2-2.1 times as wide as face; 1.3-1.4 times as wide as mesoscutum; face 1.2 times as wide as high; eyes, in lateral view, as long as temples. Face strongly punctate. Mandibles not expanded, 0.8-0.9 times as wide as long, with tooth 2 long and pointed, but teeth 1, 3 and 4 well developed (Fig. 2a). Antennae with 30 flagellomeres (32 antennomeres).

Mesosoma elongate, about 1.8 times as long as wide. Sides of pronotum covered with fine pubescence. Mesoscutum 1.2-1.3 times as wide as long, roughened anteriorly, with white pubescence covering its median 
TABLE 1. Chorebus pseudoasphodeli. Mean measurements and ranges of first instar. Body dimensions, cephalic tagma, left mandible and tail.

\begin{tabular}{|c|c|c|c|c|c|c|}
\hline & \multicolumn{3}{|c|}{ Developing larvae $^{(1)}$} & \multicolumn{3}{|c|}{ Larvae close to moulting $^{(1)}$} \\
\hline & $\mathrm{n}$ & $\mathrm{X} \pm \mathrm{SD}$ & range & $\mathrm{n}$ & $\mathrm{X} \pm \mathrm{SD}$ & range \\
\hline Body length (mm) & 15 & $0.52 \pm 0.09$ & $0.48-0.75$ & 12 & $0.87 \pm 0.05$ & $0.82-0.93$ \\
\hline Body width $(\mathrm{mm})^{(2)}$ & 15 & $0.16 \pm 0.02$ & $0.14-0.22$ & 12 & $0.23 \pm 0.01$ & $0.22-0.25$ \\
\hline Cranium length $(\mu)$ & 15 & $157.66 \pm 26.04$ & $130-210$ & 12 & $184.91 \pm 59.27$ & $137-260$ \\
\hline Cranium width $(\mu)$ & 15 & $166.06 \pm 23.84$ & $150-223$ & 12 & $278.91 \pm 33.94$ & $172-290$ \\
\hline Left mandible length $(\mu)^{(3)}$ & 15 & $31.46 \pm 9.47$ & $25-45$ & 12 & $32.93 \pm 8.70$ & $27-46$ \\
\hline Tail length $(\mu)$ & 15 & $68.66 \pm 13.66$ & $50-78$ & 12 & $55.66 \pm 23.50$ & $26-76$ \\
\hline
\end{tabular}

(1) In addition to their larger size, [the differences between lengths (Mann-Whitney $U$ test: $z=-4.483, p<0.01, N_{1}=15, N_{2}=12$ ) and widths (Mann-Whitney $U$ test: $\mathrm{z}=-4.226, \mathrm{p}<0.01, \mathrm{~N}_{1}=15, \mathrm{~N}_{2}=12$ ) of developing larvae and of larvae close to moulting are significant] they are differentiated by the ratio of head width to length since this ratio (head width/head length) is greater in larvae that are close to moulting (Mann-Whitney U test: $\mathrm{z}=-4.227, \mathrm{p}<0.01, \mathrm{~N}_{1}=15, \mathrm{~N}_{2}=12$ ).

${ }^{(2)}$ At the level of the mesothoracic segment.

${ }^{(3)}$ Length of blade.

lobe, and the lateral lobes almost bare, notauli only developed at their bases. Metapleuron with a rugose-punctate swelling; metapleural and propodeal pubescence whitish and dense. Hind femur 0.6 times as long as hind tibia.

Wings. RS sinuate (Fig. 2b). Wing length: 2.3-2.4 mm.

Metasoma. Petiole (Fig. 2c) very little widened towards its apex, 1.3 times as long as wide apically, with dense pubescence covering its surface and forming whitish apical tufts. Tergite 2 with a few basal setae. Ovipositor in the retracted position not projecting beyond the apical tergite.

Colour. Body black, with the exception of: palpi yellow; labrum orange-red; clypeus red-brown; centre of mandibles red-brown; antennae yellow; legs yellow, with the hind coxae infuscated; second metasomal segment brownish.

Body length $2.1 \mathrm{~mm}$.

Male. Like female but with: a) longer antennae, with 33 flagellomeres ( 35 antennomeres, b) with petiole more stylized, 1.6 times as long as wide apically ; c) shorter: $1.88 \mathrm{~mm}$

Differential diagnosis. This new species belongs to the "Chorebus ovalis/lateralis complex" (Griffiths, 1968), and is closest to C. asramenes (Nixon, 1937) from which it can be distinguished by the following characters: 1) Mandibles with all four teeth well developed. 2) Face strongly punctate. 3) Lateral lobes of mesoscutum almost bare. 4) Colour of labrum (orange-red) and palpi (yellow)

This species can be inserted into the keys of Griffiths (1968) (Part VI: 131) and Tobias (1995) (Vol. (III), Part $\mathrm{V}: 306)$ as follows:

Griffiths (1968):

74 Mandibles (Fig. 202, in Griffiths, couplet VI, 1968: 112) not expanded, with tooth 2 long and pointed, but tooth 3 appearing only as a projection from its side. Face weakly punctate. Lateral lobes of mesoscutum pubescent (except on their posterior half). Host: Cerodontha (Poemyza) pygmaea (Meigen, 1830) ................... . asramenes
74' Mandibles with all four teeth well developed (Fig. 2a). Face strongly punctate. Lateral lobes of mesoscutum almost bare. Host: Cerodontha phragmitophila .................. . pseudoasramenes sp. $\mathrm{n}$.

\section{Tobias (1995):}

170(171)Mandibles narrow, $2^{\text {nd }}$ denticle very acute. Anterior part of lateral lobes of mesoscutum pubescent. Figs. 116: 19; 117: 3; 118: 5; 126: 7. Body length $2.5 \mathrm{~mm}$. Parasite of Cerodontha (Poemyza) pygmaea ..... C. (S.) asramenes

170(171')Mandibles with all four teeth well developed (Fig. 2a). Lateral lobes of mesoscutum almost bare. Body length: of: $2.1 \mathrm{~mm}$; : $1.88 \mathrm{~mm}$. Parasite of Cerodontha phragmitophila ........... (S.) pseudoasramenes $\mathrm{sp.} \mathrm{n}$.

Etymology. The specific name of this species refers to $C$. asramenes (Nixon, 1943), to which it is very similar.

\section{IMMATURE STAGES}

\section{Chorebus pseudoasphodeli sp. $n$.}

Eggs and first larval instar were found in larvae of the host that were at different stages of development. Second and third larval instars and pupae were only found in hosts that had already pupated.

Egg. Fresh eggs (Fig. 3a), which apparently remain free in the hemocele, are oval, slightly pointed at one end, with a smooth transparent chorion and translucid (although slightly viscous). Size varies between 170-239 $\mu \mathrm{m}(\mathrm{X} \pm \mathrm{SD}=191 \pm 23.02, \mathrm{n}=5)$ in length and between 60-81 $\mu \mathrm{m}(\mathrm{X} \pm \mathrm{SD}=67.4 \pm 8, \mathrm{n}=5)$ in width. Eggs undergoing development (Fig. 3b), during segmentation, increase in size (330-417 $\mu \mathrm{m}, \mathrm{n}=2)$, and become more spherical, tending towards oblong at the end of their development.

Larva. $1^{\text {st }}$ instar. Some larval measurements are given in Table 1. General aspect (Fig. 3c). Body (length and width, Table 1) with head well defined and 13 body segments, caudate, vermiform, transparent, slightly curved ventrally. The last two abdominal segments almost fused together; the last one slightly modified into a short organ, blunt, rounded, in the shape of a tail (length, Table 1), with 30-45 microtrichia $(1=2 \mu \mathrm{m}, \mathrm{n}=8)$ in groups around the place where one would expect to find the 

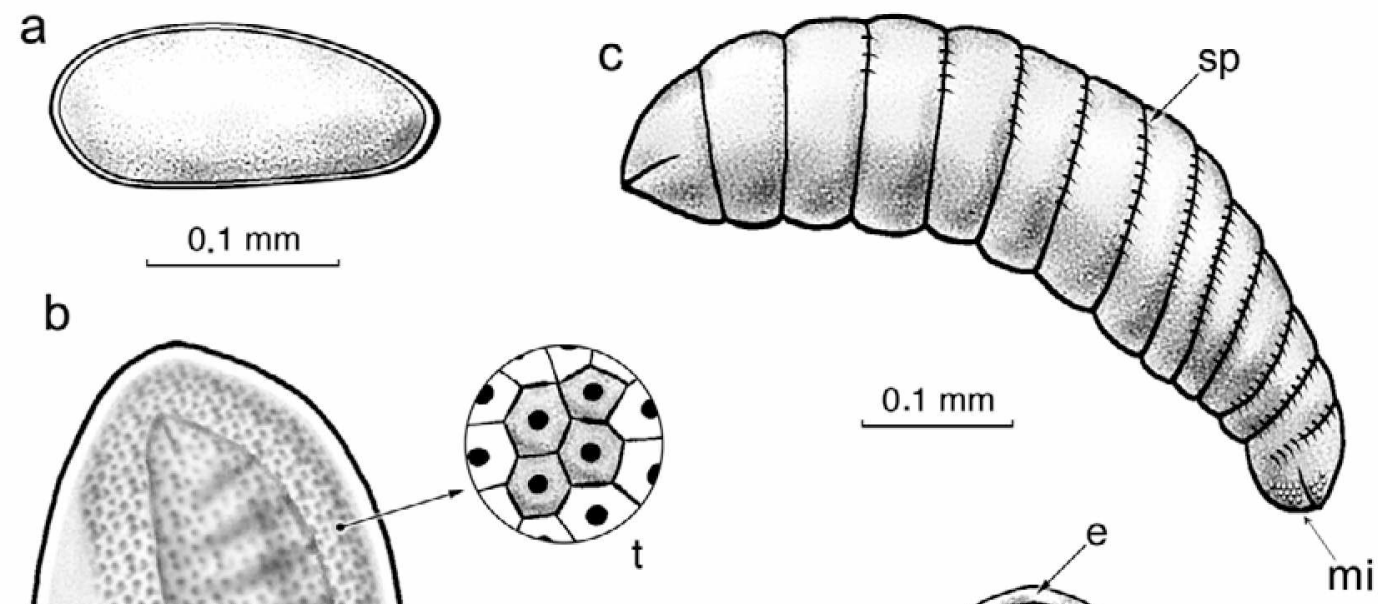

b
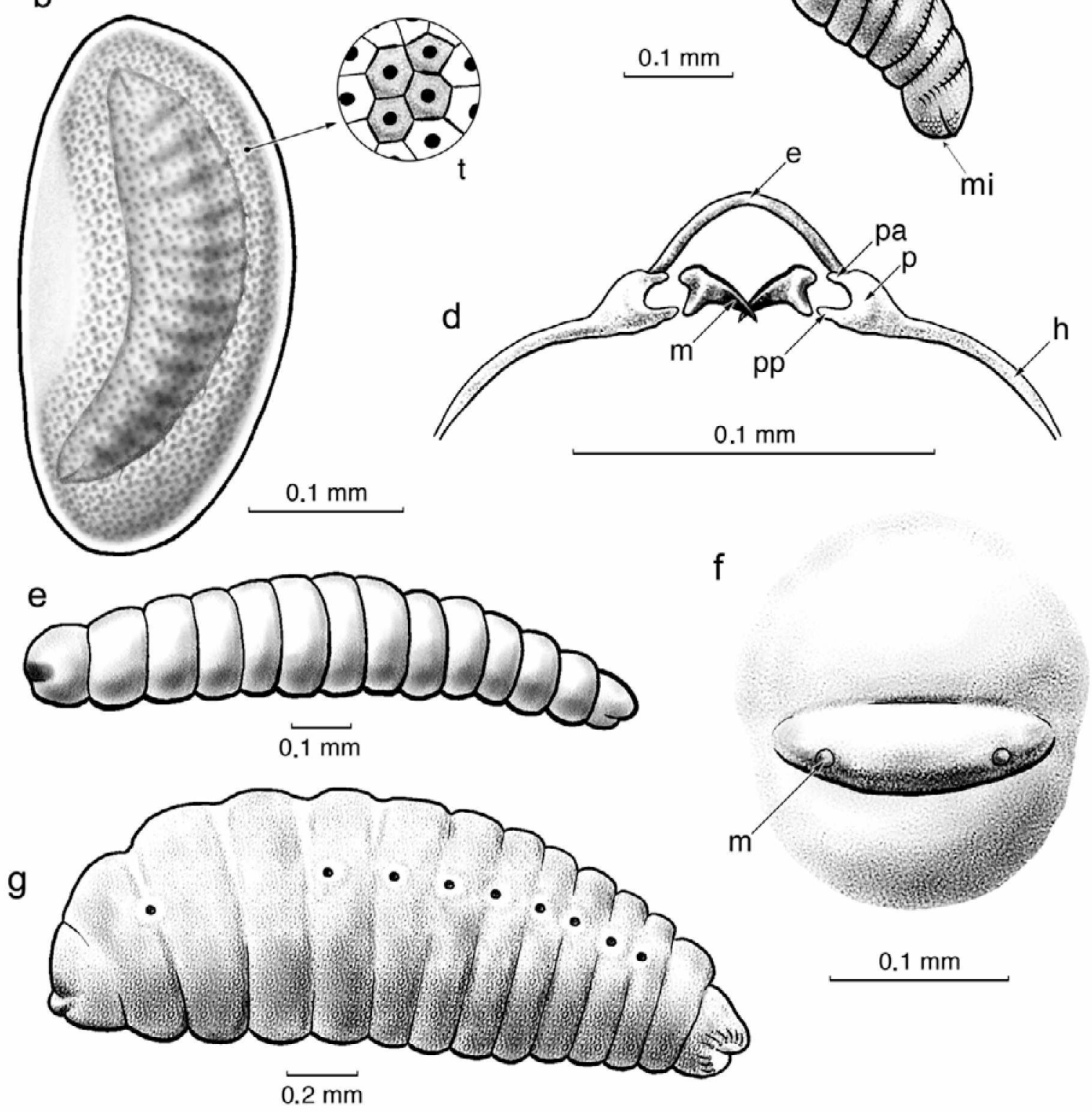

$0.1 \mathrm{~mm}$

Fig. 3. Chorebus pseudoasphodeli sp. $\mathrm{n}$. a - egg at ovoposition; $\mathrm{b}$ - larva developing inside trophamnion; $\mathrm{c}-1^{\text {st }}$ instar larva without trophamnion (lateral view); $\mathrm{d}$ - mandibles and head sclerites; e $-2^{\text {nd }}$ instar larva (lateral view); $\mathrm{f}-$ anterior view of head; $\mathrm{g}-$ $3^{\text {rd }}$ instar larva (general aspect). Lettering: $\mathrm{e}=$ epistoma; $\mathrm{h}=$ hypostoma; $\mathrm{m}=$ mandibles; $\mathrm{mi}=$ microtrichia; $\mathrm{p}=\mathrm{pleurostoma} ; \mathrm{pa}=$ anterior pleurostomal process; $\mathrm{pp}=$ posterior pleurostomal process; $\mathrm{sp}=$ spines; $\mathrm{t}=$ trophamnion.

anus. Segments 2-12, with the exception of the prothoracic and last abdominal ones, each with a row of short spines $(1=6 \mu \mathrm{m})$ on back $(\mathbf{n}=8)$ ): mesothorax (row with 6 spines), metathorax (10 spines) and abdominal segments (between 15-28 spines). Cranium (Fig. 3d) (length and width, Table 1) slightly flattened dorsoventrally, with the following differentiated but only very slightly sclero- tized sclerites: epistoma (e), pleurostoma (p), anterior (pa) and posterior (pp) pleurostomal processes and hypostoma (h). Mouthparts: Mandibles well defined, with an oblong molar lobe and with a sharp blade, slightly curved, and well sclerotized.

$2^{\text {nd }}$ instar. General aspect (Fig. 3e). Body $(1=$ $1.10-1.15 \mathrm{~mm} ; \mathrm{w}=0.30-0.35 \mathrm{~mm}, \mathrm{n}=3$ ) cylindrical, 


\section{4}

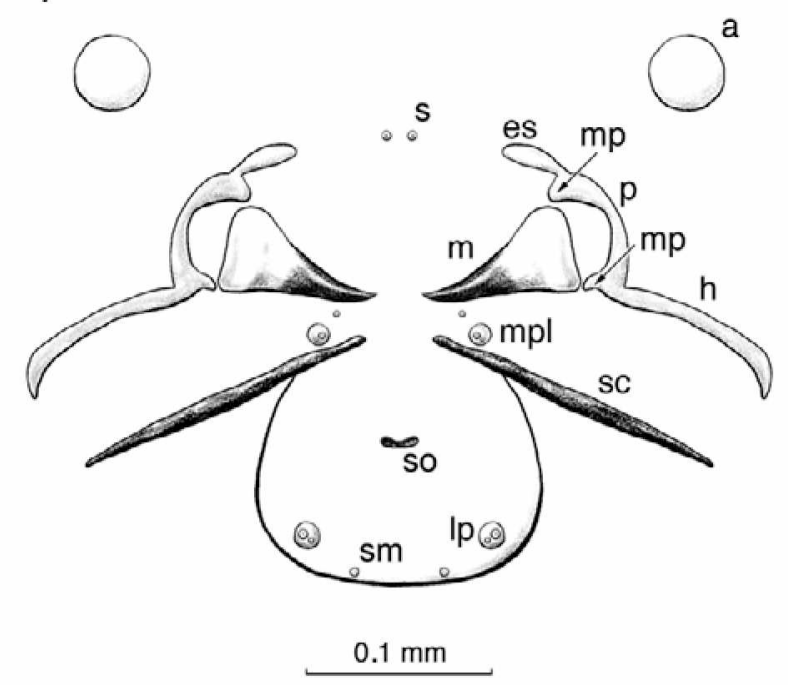

5

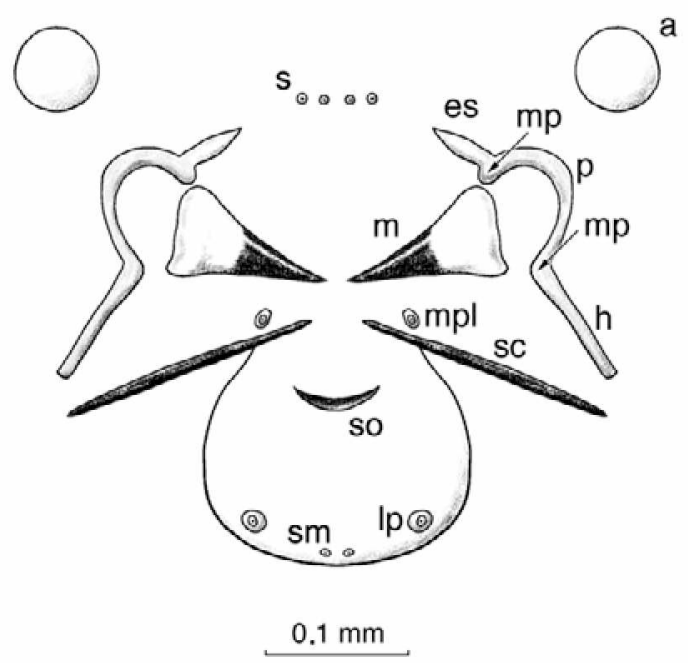

Figs 4-5. 4 - cephalic structures of final instar larva of Chorebus pseudoasphodeli sp. $\mathrm{n}$; 5 - Cephalic structures of final instar larva of Chorebus pseudoasramenes sp. n. Lettering: $\mathrm{a}=$ antennal orbit; $\mathrm{es}=$ epistomal sclerite; $\mathrm{h}=$ hypostoma; $1 \mathrm{~s}=$ labial sclerite; $\mathrm{m}=$ mandible; $\mathrm{mp}=$ mandibular processes; $\mathrm{mpl}=$ maxillary palpi; $\mathrm{pl}=$ labial palpi $\mathrm{p}=$ pleurostoma; so $=$ salivary orifice; $\mathrm{s}=$ sensilla of cranium; $\mathrm{sm}=$ sensilla of mouthparts; $\mathrm{sc}$ $=$ stipital sclerite.

fairly long relative to mesothoracic width, slightly spindle-shaped at ends. Integument bare. Cranium (Fig. 3f) without cephalic sclerites, the cephalic sclerites prominent in the first instar having completely disappeared. Mouthparts. Only the mandibles $(1 \times \mathrm{w}=8-10$ $\mu \mathrm{m} \times 8-11 \mu \mathrm{m})($ Fig. $3, \mathrm{~m})$ are present, and even they are minute.

$3^{\text {rd }}$ instar. General aspect (Fig. 3g). Typical hymenopteriform $(1=1.88-2.03 \mathrm{~mm}, \mathrm{w}=0.71-0.85 \mathrm{~mm}, \mathbf{n}=2)$, with head, the three thoracic segments and the abdominal segments well defined; yellowish-white. Integument with conical papillae $(5 \times 5 \mu \mathrm{m})$ covering thoracic and abdominal segments, except in intersegmental zones and around the spiracles and anus; posterior part of each segment surrounded by a ring of setae (40-70 per segment, mean length of setae $=6 \mu \mathrm{m})$. Nine pairs of spiracles $(\mathrm{d}=$ $10 \mathrm{~mm}$ ), with the atrium and closure apparatus well differentiated, one pair in intersegmental zone between first and second thoracic segments and one pair on anterior edge of each of the first eight abdominal segments.

Pupa. Exarate. In the single pupa examined a cocoon was not observed.

\section{Exuviae.}

Cast skin of Chorebus pseudoasphodeli. Of the five exuviae available for study only one was measured. Tegument weakly sclerotized with the exception of the spiracles, with campaniform sensilla $(\mathrm{d}=2 \mu \mathrm{m})$. Spiracles with small atrium $(\mathrm{d}=10 \mu \mathrm{m})$.

Cranium (Fig. 4) weakly sclerotized, with sensilla (s) (d $=3 \mathrm{~mm}$ ); antennal orbit (a) circular $(\mathrm{d}=40 \mu \mathrm{m})$, without papilla or differentiated sensilla; epistomal sclerite (es) unsclerotized; pleurostoma (p) sclerotized, with mandibular processes (mp); hypostoma (h) sclerotized, without hypostomal spur; stipital sclerite (sc) highly sclerotized, long.

Mouthparts. Mandibles $(\mathrm{m})(1=60 \mu \mathrm{m})$ with broad base and relatively long blade, curved, thin, smooth, unidentate, highly sclerotized; maxillary (mpl) and labial (lp) palpi circular, slightly protuberant, with two sensilla, one highly developed $(\mathrm{d}=3 \mu \mathrm{m})$ and the other minute $(\mathrm{d}=1$ $\mu \mathrm{m}$ ); salivary orifice (so) well defined; sensilla of mouthparts $(\mathrm{sm})$ very small.

\section{Chorebus pseudoasramenes sp. $\mathrm{n}$.}

Cast skin of Chorebus pseudoasramenes. Of the two exuviae available for study, only one was measured refer to only one of them. In this description, the unmentioned structures or non-specified measurements are assumed to be similar or of the same order as those of the previous species. Only differences are detailed.

Tegument with minute bluntly conical papillae. Cranium (Fig. 5), antennal orbits $(\mathrm{d}=60 \mu \mathrm{m})$; maxillary (mpl) and labial (lp) palpi oval, slightly protuberant, with a sensillum $(\mathrm{d}=4 \mu \mathrm{m})$.

\section{Discussion}

The shape and size of the eggs of C. pseudoasphodeli are similar to those reported for other species of Dacnusini (Haviland, 1922; Guppy \& Meloche, 1987), embryonic development being almost identical to that of Dacnusa areolaris (Nees von Esenbeck, 1812) (Haviland, 1922) and Dacnusa dryas (Nixon, 1948) (Guppy \& Meloche, 1987). The embryonic membrane that envelops the first instar larva, trophamnion, serous (Ivanova-Kasas, 1972), trophserosa (Caltagirone, 1959), probably has a specialized trophic function, since this is its basic function in the caudate-mandibulate larvae of Braconidae (Jackson, 1928; Simmonds, 1947 a, b; Smith, 1952).

The first instar larva of this species, according to the classifications of Clausen (1962) and Hagen (1964) is of the caudate-mandibulate type. This larva is more similar to the first instar of D. areolaris [Haviland, 1922] than to that of the only species of Chorebus described: C. posticus. Like the larva of the species of Dacnusa Haliday, 1833 it displays spines on the back of a large number of 

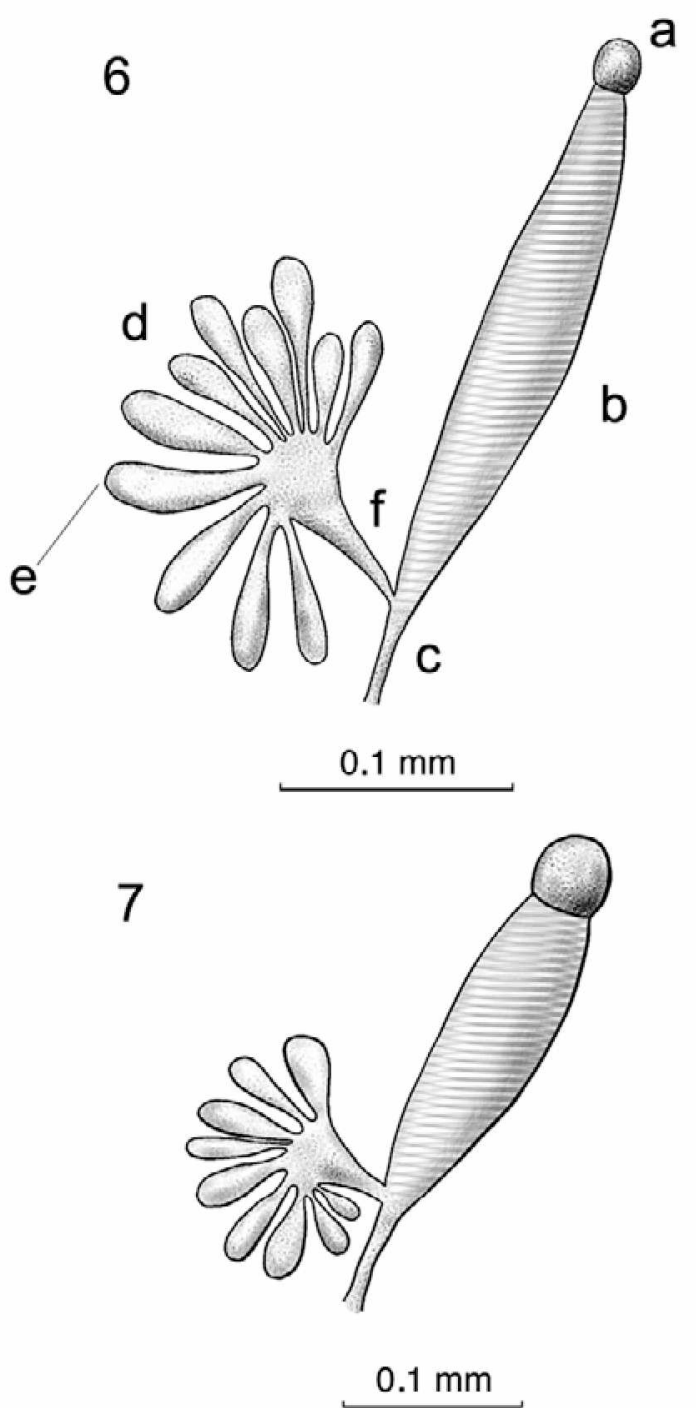

Figs 6-7. 6-venom apparatus of Chorebus pseudoasphodeli sp. $n . ; 7$ - venom apparatus of Chorebus pseudoasramenes sp. $\mathrm{n}$. The terminology used for the venom gland and reservoir parts is shown in figure 6: $\mathrm{a}=$ anterior swollen region (bulbous expansion); $\mathrm{b}=$ reservoir with spiral sculpture; $\mathrm{c}=$ reservoir neck region; $\mathrm{d}=$ venom gland; $\mathrm{e}=$ gland filament (sack); $\mathrm{f}=$ secondary venom duct.

body segments. It is possible that the mandibles, in this first instar, serve to break the chorion, as reported by Guppy \& Meloche (1987) for D. dryas. Alternatively, they could be used to kill other larvae and prevent superor multiparasitism as suggested by Hagen (1964) for the caudate-mandibulate larvae of Braconidae. The functions of the tail and spines is highly controversial (Ullyett, 1944; Hagen, 1964).

The second instar larva is similar to the mature larva, as in many Hymenoptera Parasitica. The second instar has lost its tail and spines, and the mandibles are very reduced. This latter character "presence of mandibles" separates the second instar of this species from those described for Dacnusa (Haviland, 1922; Guppy \& Meloche, 1987), but brings it closer to the third instar of C. posticus. According to Wright et al. (1946) the third instar of this species, although lacking mandibles, has a pair of weak oral papillae. Perhaps these structures are very reduced and depigmented mandibles, as in C. pseudoasphodeli.

The mature larva is very similar to that already described for C. posticus, from which it differs, mainly, in the arrangement of the setae on the tegument and the absence of cephalic papillae.

The cast skin of the final larval instar of $C$. pseudoasphodeli and C. pseudoasramenes, like that of $C$. denticurvatus, which is the only species of the genus whose final larval instar has been described in detail, shows: a) simple untoothed mandibles b) a reduced labial sclerite, c) a pleurostoma with well defined mandibular processes and d) a long stipital sclerite. The only appreciable differences between them and the above species is in the type, number and arrangement of the tegumental differentiations: sensilla, setae and papillae.

\section{VENOM APPARATUS}

The two species of Chorebus described here have a venom apparatus with the characters specified by Quicke et al. (1997) for Chorebus s.str. Both C. pseudoasphodeli (Fig. 7) and C. pseudoasramenes (Fig. 6) have: large swollen region anterior to the reservoir; an undivided reservoir; a reservoir neck region without narrowing, parallel-sided; a reservoir not more than six times longer than its maximal width; a secondary venom duct without annular/spiral sculpture; an extensively branched venom gland; a venom gland inserted at the extreme posterior end of the reservoir, and no narrow secondary venom duct. Both species can be differentiated as follows:

1 Length of the reservoir less than 4 times longer than maximal width. Number of gland filaments (sacks): $9 \quad \ldots$. C. pseudoasphodeli

1' Length of the reservoir between 4-6 times longer than maximal width. Number of gland filaments (sacks): $11 \ldots$ C. pseudoasramenes

From the data available on the preimaginal states and morphology of the venom apparatus of the Dacnusini, it is clear that further descriptions are necessary, both of the larvae and the venom apparatus, before inferring phylogenetic relationships from their morphological features. Thus, although Quicke et al. (1997) observed morphological differences between the venom apparatus of $C$. posticus and those of other Chorebus s.str., which allow the separation of this species from the rest of the genus, this is not confirmed by significant differences in the preimaginal instars. The most marked differences between the mature larvae of C. posticus and those of Chorebus species, which are described in greatest detail: $C$. denticurvatus, C. pseudoasphodeli and C. pseudoasramenes, lie in the arrangement of the setae on the tegument and the absence of cephalic papillae. In the immature larvae, the only potentially interesting aspect is the absence of spines on the tegument of the first instar larva of C. posticus and the presence of such structures in C. pseudoasphodeli. Finally, although the number of larval instars in the last species differs from that in C. posticus, this is not impor- 
tant since despite the tendency of endoparasitoid Hymenoptera to show fewer than 5 larval instars (Quicke, 1997), it may vary even within the same genus (Hagen, 1964).

ACKNOWLEDGEMENTS. We wish to thank C. van Achterberg (National Museum of Natural History, Leiden), T. Finlayson (Simon Fraser University, Burnaby, Canada) and D. Quicke (Imperial College, UK), for their observations and critical reading of the manuscript. G.C.D Griffiths (University of Alberta, Canada) and I. Docavo (Universidad de Valencia, España), confirmed the determinations of the parasitoids. Michel Martínez (Laboratoire de Faunistique Écologique, I.N.R.A., France) confirmed the determination of Cerodontha phragmitophila. This study was carried out in the laboratories of the Departamento de Protección Vegetal, U.V.I.A. Financial support was provided by the Junta de Castilla y León, project SA 18/96, and Fundación Entomológica "Torres-Sala".

\section{REFERENCES}

Caltagirone L.E. 1959: The Biology of Pontania pacifica Marlatt (Hymenoptera: Tenthredinidae), and its Parasites and Inquilines. Ph.D. Thesis, Univ. Calif., $630 \mathrm{pp}$.

$\check{C}_{A P E K}$ M. 1970: A new classification of the Braconidae (Hymenoptera) based on the cephalic structures of the final instar larva and biological evidence. Can. Entomol. 102: 846-875.

Clausen C.P. 1962: Entomophagous Insects. McGraw-Hill Book, New York \& London, $688 \mathrm{pp}$.

EDSON K.M. \& VINSON S.B. 1979: A comparative morphology of the venom apparatus of female braconids (Hymenoptera: Braconidae). Can. Entomol. 111: 1013-1024.

Evans H.E. 1987: Order Hymenoptera. In: Stehr F.W. (ed.): Immature Insects. Kendall/Hunt Publishing Company, Dubuque, Iowa, pp. 597-710.

FinlaYson T. 1987: Ichneumonoidea. In: Stehr F.W. (ed.): Immature Insects. Kendall/Hunt Publishing Company, Dubuque, pp. 649-664.

Finlayson T. \& Hagen K. 1979: Final-Instar Larvae of Parasitic Hymenoptera. Pestology Centre, Department of Biological Sciences, Simon Fraser University, Burbany, B.C., Canada, $111 \mathrm{pp}$.

GrifFITHS G.C.D. 1968: The Alysiinae (Hym.: Braconidae) parasites of the Agromyzidae (Diptera). VI. The parasites of Cerodontha Rondani s.1. Beitr. Entomol. 18: 63-152.

Guppy J.C. \& Meloche F. 1987: Life history and description of the immature stages of Dacnusa dryas (Nixon) (Hymenoptera: Braconidae), a European parasite of the alfalfa blotch leafminer (Diptera: Agromyzidae) in eastern Canada. Can. Entomol. 119: 281-285.

HAGEN K.S. 1964: Developmental stages of parasites. In: P Debach (ed.): Biological Control of Insects Pests and Weeds. Chapman \& Hall, London, pp. 186-246.

Haviland M.D. 1922: On the larval development of Dacnusa areolaris Nees (Braconidae), a parasite of Phytomyzinae (Diptera), with a note on certain chalcid parasites of phytomyzids. Parasitology 14: 167-173.

IVAnova-Kasas O.M. 1972: Polyembryony in insects. In: Counce S.J., Waddington C.H. (eds): Developmental Systems: Insects, Vol. I. Academic Press, London, pp. 243-271.
JACKSON D.J. 1928: The biology of Dinocampus (Perilitus) rutilans Nees, a braconid parasite of Sitona lineata L. Part I. Proc. Zool. Soc. London 1928: 597-630.

Pardo X., Tormos J. \& Verdú M.J. 2001: Description of Chorebus denticurvatus sp. nov. and the exuviae of its final larval instar (Hymenoptera: Braconidae: Alysiinae). Florida Entomol. 84: 652-658.

Quicke D.L.J. 1997: Parasitic Wasps. Chapman \& Hall, London, $470 \mathrm{pp}$.

Quicke D.L.J. \& ACHTerberg VAN C. 1990: Phylogeny of the subfamilies of the family Braconidae (Hymenoptera). Zool. Verhand. 258: 1-95.

Quicke D.L.J., Tunstead J., Falcó J.V. \& Marsh P.M. 1992: Venom gland apparatus in cyclostome braconid wasps with special reference to the subfamily Doryctinae (Insecta: Hymenoptera: Braconidae). Zool. Scr. 21: 403-416.

Quicke D.L.J., AChTERBERg C. VAN \& GodFray H.C. 1997: Comparative morphology of the venom gland and reservoir in opiine and alysiine braconid wasps (Insecta: Hymenoptera: Braconidae). Zool. Scr. 26: 23-50.

SHORT J.R.T. 1952: The morphology of the head of larval Hymenoptera with special reference to the head of Ichneumonoidea, including a classification to the final instar larvae of the Braconidae. Trans. R. Entomol. Soc. Lond. 103: 27-84.

SHORT J.R.T. 1978: The final larval instars of the Ichneumonidae. Mem. Amer. Entomol. Inst. 25: 508 pp.

SimE K.R. \& WAHL D.B. 1998: Taxonomy, mature larva and observations on the biology of Gnamptopelta obsidianator (Brullé) (Hymenoptera: Ichneumonidae: Ichneumoninae). $J$. Hym. Res. 7: 157-164.

SiMMONDS F.J. 1947a: Improvement of the sex-ratio of a parasite by selection. Can. Entomol. 79: 41-44.

SImmondS F.J. 1947b: The biology of the parasites of Loxostege sticticalis L. In North America - Bracon vulgaris (Cress.) (Braconidae: Agathinae). Bull. Entomol. Res. 38: 145-155.

SMITH O.J. 1952: Biology and behavior of Microctonus vittatae Muesebeck (Braconidae). Univ. Calif. Publ. Entomol. 9: 315-344.

ToBIAS W.I. 1995: Subfamily Alysiinae. In: Medvedev G.S. (ed.): Keys to the Insects of the European Part of the USSR. Vol. III. Hymenoptera. Part V. Science Publishers Inc., Lebanon, pp. 156-386.

ULLYETT G.C. 1944: On the function of the caudal appendage in primary larvae of parasitic Hymenoptera. J. Entomol. Soc. S. Africa 7: 30-37.

WAHL D.B. 1984: An improved method for preparing exuviae of parasitic Hymenoptera. Entomol. News 95: 227-228.

WHARTON R.A. 1977: New World Aphaereta species (Hymenoptera: Braconidae) with a discussion of terminology used in the tribe Alysiini. Ann. Entomol. Soc. Am. 70: 782-803.

Wharton R.A., MARSH P.M. \& Sharkey M.J. 1997: Manual of the New World Genera of the Family Braconidae(Hymenoptera). Special publications of the International Society of Hymenopterists, Washington D.C., 439 pp.

Whitfield J.B 1992: The polyphyletic origin of endoparasitism in the cyclostome lineages of Braconidae (Hymenoptera). Syst. Entomol. 17: 273-286.

Wright D.W., Geering Q. \& Ashry D.G. 1946: The insect parasites of the carrot fly, Psila rosae. Fab. Bull. Entomol. Res. 37: $507-529$.

Received May 16, 2002; revised January 6, 2003; accepted March 18, 2003 